\title{
Apropiación del espacio en La Serranía de Manacacías, Orinoquía colombiana
}

\author{
Space Appropiation in La Serrania de Manacacias, \\ Colombian Orinoquía
}

Apropriação do espaço na Serrania de Manacacias, Orinoquia Colombiana

Raúl Iván Clavijo Mejía*

Recibido: 29 de febrero de 2019

* Universidad Santo Aprobado: 10 de julio de 2019

Doi: https://www.doi.org/10.12804/revistas.urosario.edu.co/territorios/a.7625

Para citar este artículo:

Clavijo Mejía, R. I. (2020). Apropiación del espacio en La Serranía de Manacacias, Orinoquía colombiana. Territorios, (42-Especial), 1-30. https://www.doi.org/10.12804/revistas.urosario.edu.co/territorios/a.7625

Tomás (Colombia).

Correo electrónico: raulclavijo@usantotomas.edu. co. ORCID: https://orcid. org/0000-0001-8726$513 X$ 
Palabras clave

Apropiación del espacio, espacio rural, territorio, actividades productivas, tenencia de la tierra.

Keywords

Agrarian territory, conservation territory, territorial knowledge, protected natural area.

Palavras-chave

Apropriação do espaço, espaço rural, território, atividades produtivas, propriedade da terra.

\section{tersitarias 42-Especial}

\section{RESUMEN}

En este artículo se desarrolla un análisis de las formas de apropiación del espacio y su impacto en elementos clave de la estructura socioeconómica de las veredas Puerto Castro y La Cristalina, del municipio de San Martín de los Llanos, departamento del Meta. Se identifican diferencias sustanciales en las formas de apropiación espacial y las herramientas utilizadas por los actores que a lo largo del tiempo han tenido presencia en esta zona. Las entrevistas semiestructuradas se aplicaron entre 2017 y 2018 a pobladores - tanto propietarios de los predios, como administradores-, que habitan la zona desde la primera mitad del siglo Xx. El contacto in situ con los pobladores y la visita a los lugares que marcaron la historia de ambas veredas permiten profundizar en las consecuencias de las formas de apropiación espacial en distintos periodos históricos, así como en su impacto en términos territoriales, productivos, poblacionales y de estructura de la tenencia de la tierra.

\section{ABSTRACT}

This article analyses the space appropriation forms and their impact on essential elements of the socio-economic structure of the Puerto Castro and La Cristalina paths, of the municipality of San Martín de los Llanos, department of Meta. The study allowed the identification of substantial differences in the forms of spatial appropriation and the tools used by the actors that, over time, have had a presence in this area. The semi-structured interviews were applied between 2017 and 2018 to residents who inhabit the area since the first half of the twentieth century, both to property owners and administrators. The in-situ contact with the inhabitants and the visit to the places that marked the history of both paths allowed deepening the consequences of the forms of spatial appropriation in different historical periods, as well as their impact in territorial, productive, population, and land tenure structures.

\section{RESUMO}

Neste artigo se desenvolve uma análise das formas de apropriação do espaço e seu impacto em elementos chave da estrutura socioeconômica das vilas Puerto Castro e La Cristalina, do município de San Martín de los Llanos, departamento de Meta. Se identificam diferenças substanciais nas formas de apropriação espacial e as ferramentas utilizadas pelos atores que ao longo do tempo têm tido presença nesta zona. As entrevistas semiestruturadas se aplicaram entre o ano $2017 \mathrm{e}$ o 2018 a habitantes que moravam na zona desde a primeira metade do século xx, tanto a proprietários dos prédios quanto aos administradores. O contato in situ com os habitantes, e a visita aos lugares que marcaram a história de ambas as vilas, permite aprofundar nas consequências das formas de apropriação espacial em diferentes períodos históricos, assim como o seu impacto em termos territoriais, produtivos, populacionais e de estrutura da propriedade da terra. 


\section{Introducción}

Algunos trabajos realizados en los Llanos Orientales (Arias, 2004; Gouëset, 1999 Carabalí, 2009, Rojas-López, 2016) dan cuenta de que la apropiación del espacio llanero y sus representaciones, así como la construcción de la noción de territorio, obedecen a procesos sociales, políticos, económicos y de violencia que "no son estáticos u homogéneos, sino mosaicos de temporalidades desiguales, herencias ligadas a su dilatado pasado e innovaciones asociadas a emergentes ruralidades" (Rojas-López, 2016, p. 60). En este artículo, el análisis sobre las veredas Puerto Castro y La Cristalina parte de estudiar las causas y consecuencias de las diferentes dinámicas de apropiación espacial, teniendo en cuenta los distintos actores que confluyen en diferentes épocas. Así pues, se espera dar elementos al lector para comprender las causas y consecuencias de estos procesos de apropiación, así como los impactos en 5 aspectos centrales (tabla $\mathbf{1}$ ).

Para lograr ese propósito, las visitas de campo a lo largo de un año fueron determinantes en el proceso de recopilación de información. Se desarrollaron visitas a las veredas cada dos o tres meses entre 2017 y 2018 , con una duración de entre 4 a 5 días cada una. La elaboración de los mapas veredales es producto de conversaciones en donde los entrevistados resaltaron los lugares clave de la vereda para cada uno de los periodos históricos identificados. A pesar de que son ocho las entrevistas semiestructuradas, de las cuales tres fueron recuperadas de los archivos de Parques Nacionales Naturales (PNN), es importante resaltar que el criterio principal para definir a los informantes clave fue el tiempo de permanencia en la vereda. Aunque no se tuvo en cuenta a las personas recién

Tabla 1. Aspectos a analizar

\begin{tabular}{|l|l|}
\hline \multicolumn{1}{|c|}{ Aspecto } & \multicolumn{1}{c|}{ Definición } \\
\hline Organización social & $\begin{array}{l}\text { Grupo de personas que interactúan entre sí, a partir de determinadas } \\
\text { relaciones de poder y producción. }\end{array}$ \\
\hline Actividad productiva & $\begin{array}{l}\text { Proceso que se realiza para la obtención de bienes o servicios destinados a } \\
\text { cubrir las necesidades básicas. }\end{array}$ \\
\hline $\begin{array}{l}\text { Estructura de la tenencia } \\
\text { de la tierra }\end{array}$ & $\begin{array}{l}\text { Relación definida jurídica o consuetudinariamente, entre grupos de personas o } \\
\text { individuos, que determina quién puede utilizar qué recursos, durante cuánto } \\
\text { tiempo y bajo qué circunstancias. }\end{array}$ \\
\hline Ejercicio de territorialidad & Formas de ejercer control y dominio en un territorio. \\
\hline Apropiación espacial & $\begin{array}{l}\text { Proceso de ocupación y poblamiento a partir del cual se le otorgan cargas } \\
\text { simbólicas e identitarias al espacio, que da paso a la construcción de territorio. }\end{array}$ \\
\hline
\end{tabular}


llegadas a la zona, sus historias pueden ser recopiladas y analizadas a la luz de nuevos estudios, así como la inclusión de información cuantitativa.

Al entender que el espacio es apropiado "por un grupo social para asegurar su reproducción y la satisfacción de sus necesidades vitales, que pueden ser materiales o simbólicas" (Giménez, 2001, p. 5), en este documento el análisis de las dinámicas de apropiación espacial, se amplía al comprender las veredas "como un sistema socioeconómico que se expresa, a su vez, en un espacio objeto de disputa" (Cubillos, 2011, p. 18). En la actualidad, el análisis del espacio rural, así como del concepto de territorio están enmarcados en la integración de las actividades agrícolas a los mercados nacionales e internacionales. Sumado a esto, aspectos referentes a la conservación ambiental, la violencia como método de acaparamiento de tierras, el extractivismo y el agronegocio hacen parte de los estudios latinoamericanos sobre este tema. Ávila Sánchez (2015) destaca que en los estudios recientes del espacio rural latinoamericano, los enfoques en la dinámica

Figura 1. Ubicación geográfica del área de estudio

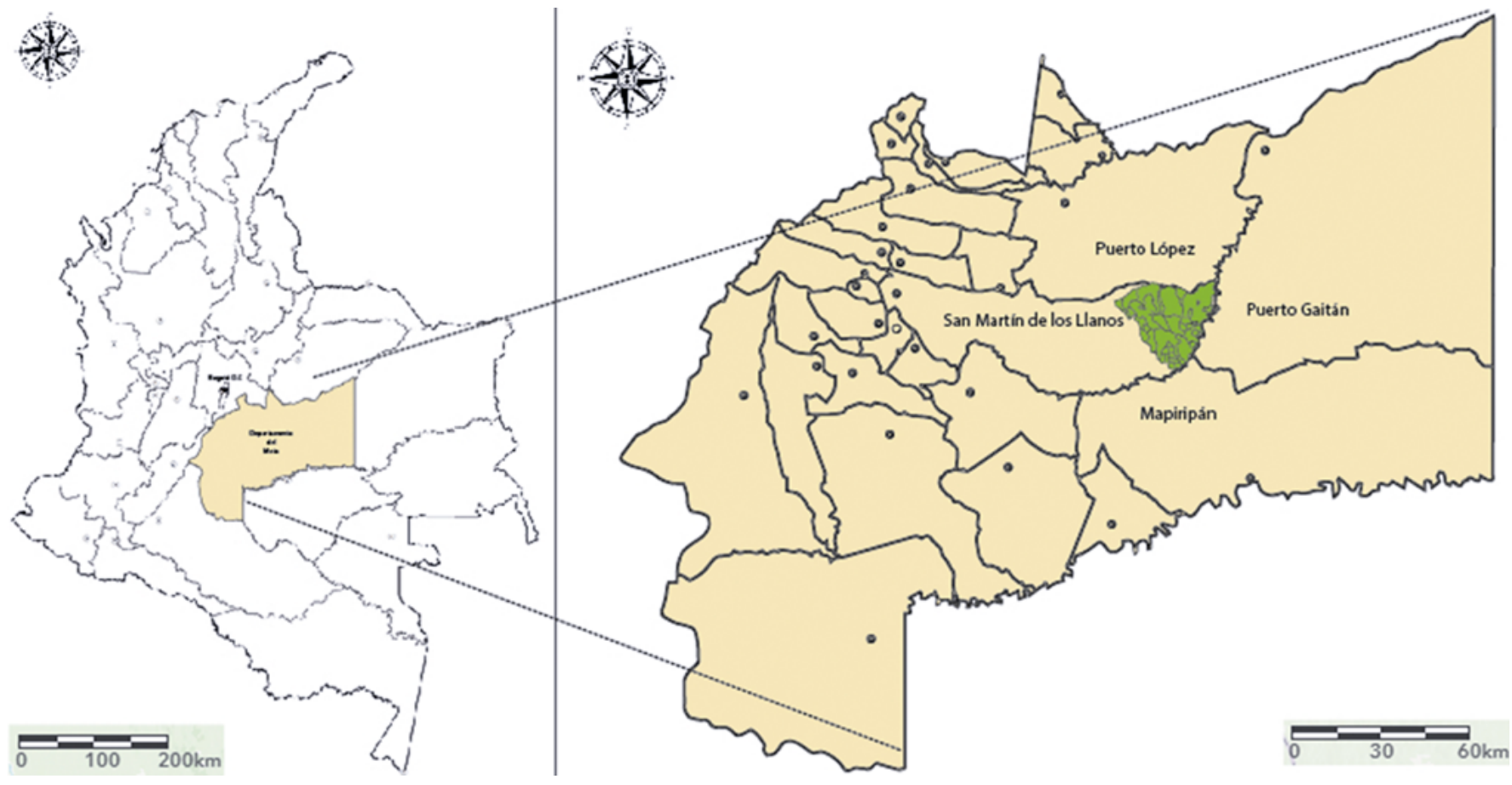

Fuente: Adaptado de Parques Nacionales Naturales (2017). 
de la organización social, productiva y cultural están mediados por el territorio y sus transformaciones. Esta referencia al territorio constituye un elemento central en tanto el núcleo de los análisis parte de la relación del hombre con su entorno, así como de entender las particularidades regionales, locales y veredales.

Como se evidencia en las figuras 1 y 2 , la vereda La Cristalina limita al norte con el Caño Garibay y el municipio de Puerto López; al oriente con el río Manacacías, el municipio de Puerto Gaitán y la vereda Comejenal; al sur con el Caño Cumaral y con la vereda Puerto Castro; al occidente con la vereda Cumaralito (figura 2). La vereda Puerto Castro limita al norte con el Caño Cumaral y la vereda La Cristalina; al oriente con el río Manacacías, el Municipio de Puerto Gaitán y la vereda Kioskos, al occidente limita con el Caño Pauto; al sur limita con el caño Pauto, el río Manacacías y el municipio de Mapiripán (figura 2).

Figura 2. Límites de las veredas Puerto Castro y La Cristalina

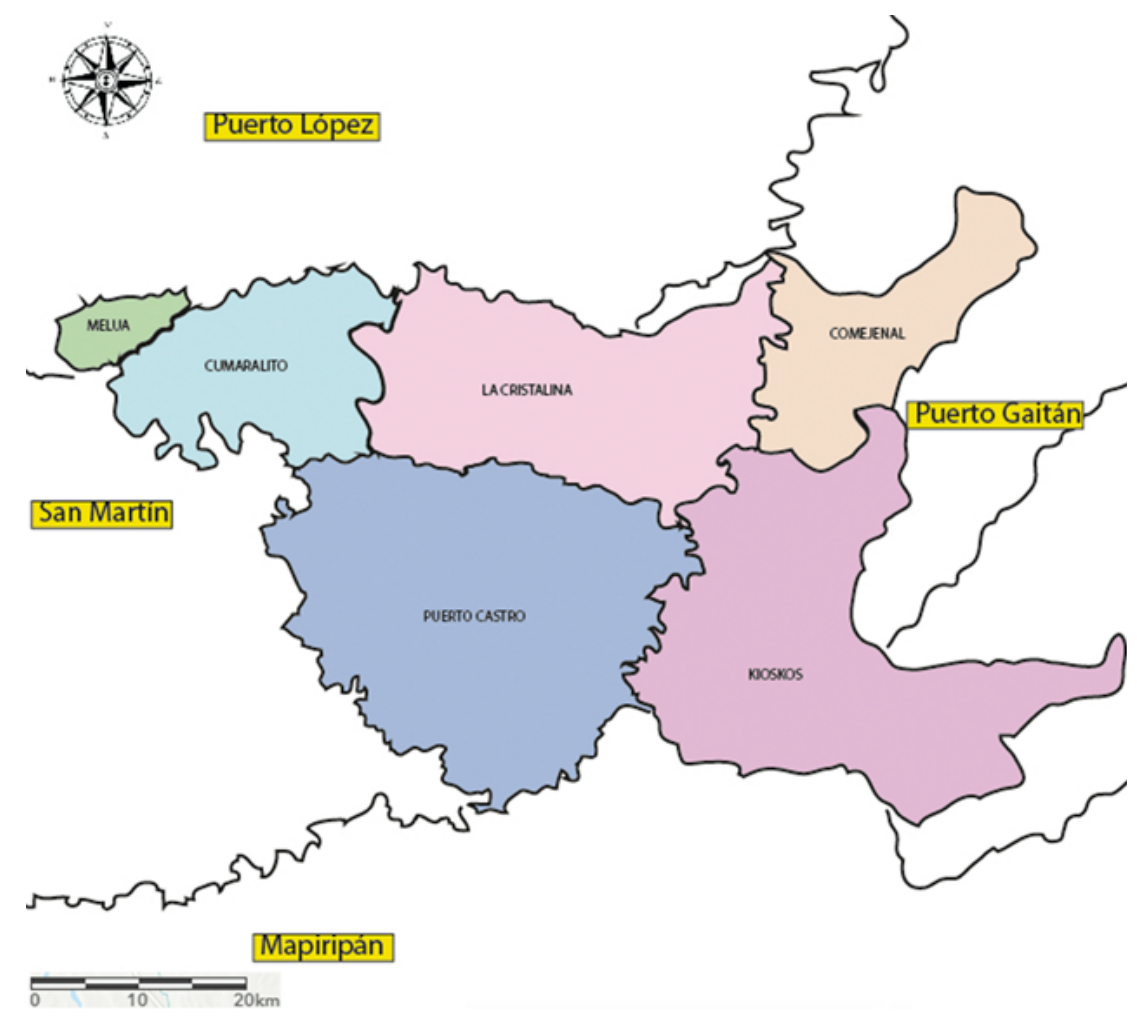

Fuente: Adaptado de Parques Nacionales Naturales (2017). 
Colonización de La Serranía: efecto llamada y fundación de hatos ganaderos (1960-1980)

Luego del asesinato de Jorge Eliécer Gaitán el 9 de abril de 1948, la convulsión sociopolítica y los brotes de violencia generaron flujos migratorios hacia los territorios nacionales — zonas de frontera como los Llanos Orientales-. Autores como Molano (1989) y Jaramillo, Mora y Cubides (1986) coinciden en afirmar que la colonización de los Llanos durante la segunda mitad del siglo XX se produjo a raíz de cinco corrientes migratorias, cuyo rasgo común es haber sido consecuencia de la violencia.

La primera corriente data del periodo conocido como La Violencia. Cientos de campesinos —en su mayoría liberalestuvieron que salir de los departamentos de Boyacá, Santander, Huila, Caldas, Tolima y Cundinamarca hacia los territorios de frontera en el oriente colombiano. La segunda corriente se originó por la movilización de las columnas en marcha del naciente Bloque Sur - que se transformó en las FARC en 1964- hacia la zona de El Pato-Guayabero. La tercera corriente se produjo luego del rompimiento de las relaciones entre Rojas Pinilla y el Partido Comunista. La cuarta corriente ocurrió por los planes de rehabilitación y colonización dirigida durante el gobierno de Rojas Pinilla. La quinta corriente migratoria se dio por la bonanza cocalera y maderera de los años 70 y 80.
La Serranía de Manacacías no fue ajena a estos procesos de colonización y violencia. Por tradición política, San Martín había sido un pueblo de liberales, razón por la cual a finales de la década de 1940, muchos ganaderos y campesinos de este pueblo abandonaron sus fincas y el municipio. De hecho, muchos de los propietarios actuales de los hatos ubicados en La Serranía tuvieron que dejar sus primeras fincas ganaderas y huir, moviendo su ganado - si tenían la posibilidad - a otras fincas en San Carlos de Guaroa a orillas del río Meta, donde los sucesos de $\mathrm{La}$ Violencia tuvieron un menor impacto.

\section{Colonización en Puerto Castro: una "tierra sin dueño"}

El proceso de colonización en La Serranía se destaca por haber tenido como eje central la actividad ganadera. Los primeros colonos de Puerto Castro y La Cristalina consolidaron su apropiación espacial a partir de la fundación de hatos y la utilización del ganado como herramienta de territorialidad. Aunque muchos de los propietarios de estos colonizaron La Serranía con ganado comprado a préstamo, algunos utilizaron sus sabanas para esconder las reses luego del estallido de la primera ola de La Violencia.

Luego de la instalación de la Junta Militar presidida por Rojas Pinilla, muchos campesinos y ganaderos que habían salido de la zona en la primera ola de violencia, volvieron a buscar tierras "baldías" o 
“despobladas" en la sabana de San Martín. Fue entonces cuando La Serranía apareció como una opción de colonización ganadera al considerarse un espacio sin dueños ni ocupantes. En este contexto, campesinos y ganaderos emprendieron viajes a caballo en la búsqueda de nuevas tierras - algunos de las cabezas de ganado que habían dejado en La Serranía- y dieron inicio a la fundación de hatos en lo que hoy se conoce como la vereda Puerto Castro. La fundación de hatos se dio en efecto dominó, los colonos que se asentaban en La Serranía promovían la colonización mediante el efecto llamada, definido por García Abad (2003) como "la capacidad de atracción de familiares y paisanos, a aquellos lugares a los que con anterioridad se han desplazado los pioneros" (p. 347).

Aunque la idea que los colonos tenían de La Serranía era la de un espacio disponible para ser apropiado, grupos de indios guahíbos vivían en las amplias extensiones de La Serranía cultivando yuca y maíz a las orillas de los caños y ríos, pescando y cazando. Con la llegada de los colonos, muchos indígenas fueron desplazados, algunos asesinados y otros más se convirtieron en trabajadores de los nuevos propietarios de La Serranía. De esta manera, emergieron nuevas relaciones sociales y productivas de acuerdo a la oferta de los recursos, los cuales a su vez dieron pie al "establecimiento de relaciones de complementación y, de paso, a la articulación de los espacios y el paulatino establecimiento de sistemas jerarquizados de relaciones espaciales" (Fajardo, s.f., p. 6). La ocupación de los territorios, afirma Fajardo (s.f.), corresponde a la del espacio y al establecimiento de asentamientos con nuevos sistemas de poblamiento, una nueva actividad productiva, nuevas relaciones de producción y una nueva organización social.

\section{Colonización en La Cristalina: la vereda de Ishido Kawai}

El proceso de colonización y poblamiento al norte del caño Cumaral -límite natural entre las veredas Puerto Castro y La Cristalina - se remonta a la mitad del siglo XX. Los primeros hatos fundados fueron Tamanaco y Caribe, después de los cuales aparecieron Buenos Aires, Potosí, Pozones y San Antonio - futuro Cejalito-. El Hato San Antonio fue fundado a mediados del siglo XX por un valluno llamado Tulio Ossa, quien se asoció a un alemán de nombre Ricardo Boffer. A finales de la década del 60, Tulio Ossa y Boffer le vendieron la finca con ganado a un japonés de nombre Ishido Kawai, un esmeraldero dueño de una joyería en Bogotá. Desde el momento en que San Antonio pasó a manos de Kawai, el hato recibió el nombre de Cejalito, debido a la gran cantidad de palma de Seje que había a orillas del río Manacacías. A medida que crecía la ganadería, los japoneses se apropiaron de las tierras baldías que la finca tenía hacia el sur, donde llegaron hasta el caño Cumaral, y hacia el occidente, a la
${ }^{1}$ Se desconocen las razones del interés de Kawai en esas tierras. 


\section{territorias 42-Especial}

finca que hoy se conoce como Las Vegas. De esta manera, Cejalito creció hasta tener alrededor de 45000 ha. Cejalito estuvo dividido en 9 fundos, cada uno con un encargado responsable de la ganadería y de las quemas de pasto. Adicionalmente, cada uno de los fundos del hato tenía una pequeña represa para que el ganado tomara agua en épocas de verano y varios de ellos tenían casa propia. Los japoneses también construyeron carreteras y puentes sobre los caños y adquirieron maquinaria como retroexcavadoras, buldóceres y motoniveladoras.

Para realizar todas estas obras, algunos pobladores afirman que Kawai solicitó un préstamo con el Banco Real de Brasil y sus filiales en Panamá y Colombia, por 100 millones de pesos cada uno. Otras personas relacionan la capacidad económica demostrada por el propietario de Hato Cejalito con el narcotráfico. De acuerdo a Castillo (1987), Kawai hacía lavado de activos para los hermanos Rodríguez Orejuela y según comentan diferentes habitantes de la zona, en su propiedad se había adecuado una pista de $1700 \mathrm{~m}$, por medio de la cual "un avión traía cigarrillos Marlboro y whiskey y sacaba marihuana" (Sierra, comunicación personal, 2017). Lo anterior llevó a que, a principios de la década de 1980, Ishido Kawai fuera arrestado en Nueva York (Castillo, 1987). Durante cuatro años, los dos administradores japoneses intentaron mantener el hato y comenzaron a vender el ganado para avanzar en el pago de deudas. Pronto se hizo evidente que este no era rentable y comenzó a ser invadido por colonos. En ese momento, los administradores tomaron la decisión de parcelar. Muchos trabajadores del gran Hato Cejalito se convirtieron en propietarios de pequeños fundos $\mathrm{y}$, al igual que en Puerto Castro, el efecto llamada surtió efecto. Numerosos habitantes de San Martín y pueblos cercanos llegaron a La Cristalina para buscar suerte y quedarse en una vereda prometedora.

\section{Narcotráfico y paramilitarismo: un nuevo actor en La Serranía (1980-2005)}

Hacia 1986, Héctor Buitrago había expandido su zona de influencia por toda La Serranía, y como propiciador de la economía coquera, había promovido la fundación de los caseríos El Tropezón y La Jungla. "Los Buitragueños" llegaron a la zona con apenas 7 personas, pero con el paso del tiempo el número de integrantes fue aumentando. Este incremento de tropas fue el resultado de la poca oferta laboral, la vinculación a este grupo ofrecía la posibilidad de recibir un ingreso que oscilaba entre los \$130000 y \$300000 COP mensuales (Fundación Puerto Rastrojo, 2014), 300\% más de lo que un vaquero en un jornal normal podría ganar.

El control de "Los Buitragueños" era tal, que quienes entraban a La Serranía debían ser recomendados o conocer a algún habitante de la zona. Paralelo a su presencia, inició un fuerte despliegue armado 
del Muerte a Secuestradores (MAS), y hacia la década de los noventa llegaron las Autodefensas Unidas de Colombia (AUC). Aunque estos tres grupos eran paramilitares, no existía una estructura de mando unificada dentro de la zona, por tal razón se fundó el Bloque Centauros. La actividad productiva de dicho bloque fue el narcotráfico, con la particularidad de que en las veredas no se ubicaron los cultivos de hoja de coca. Como se muestra en la figura 3, existía en La Serranía una ruta estipulada y respetada que se utilizaba para la mencionada actividad. Puerto Castro y La Cristalina se convirtieron en los sitios para la fabricación de la pasta de coca, su transporte y posterior distribución. Se apropiaron del espacio veredal a través

Figura 3. Ruta del narcotráfico

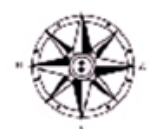

Puerto López

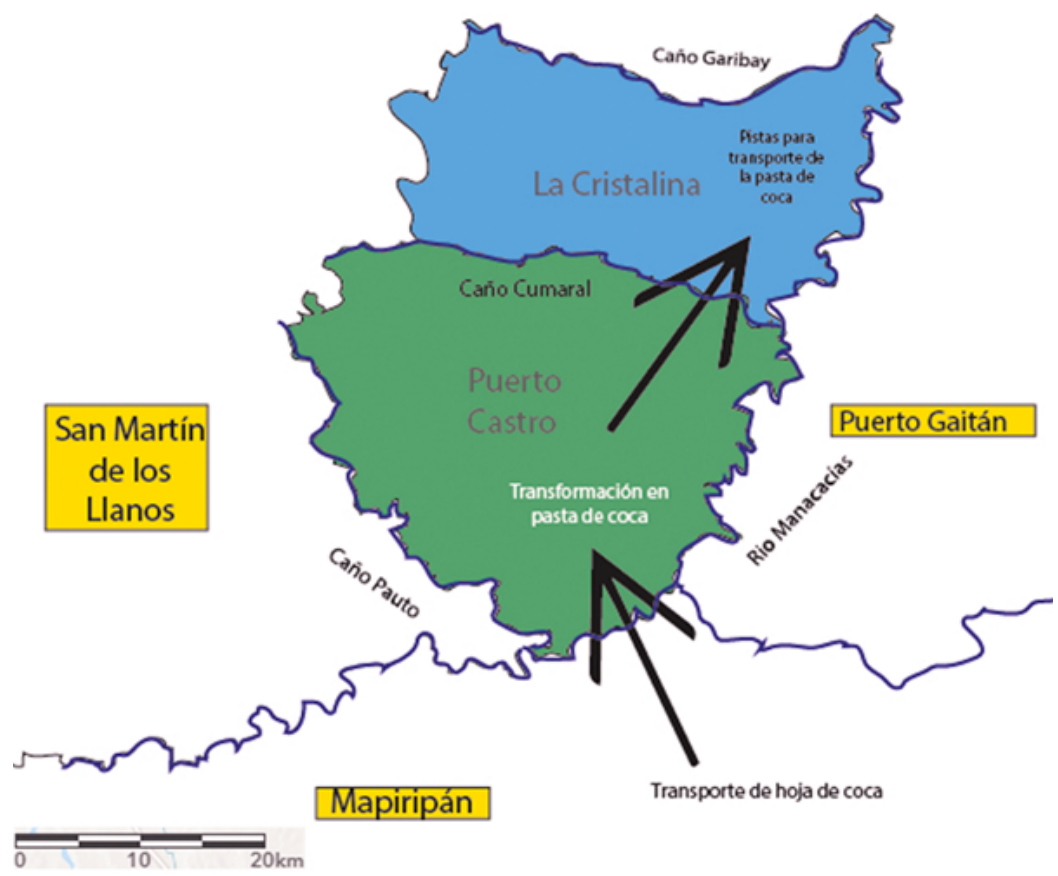


2 Ver: httpxs://www. eltiem po.com / ar chivo/documento / MAM-704846

3 Ver: https://www.eltiempo.com/archivo/documento/CMS-8435506; https://www.semana. com/nacion/articulo/ paramilitares-asesinatovillavicencio-canibalismo/361905-3; https:// verdadabierta.com/lasmasacres-desconocidasdel-bloque-centauros/; https://verdadabierta. com/cony-confiesa-como-los-paras-desaparecian-a-sus-victimas-enmeta/

${ }^{4}$ Ver: https://www.semana.com/opinion / articulo/aura-patriciabolivar-jaime-restitucionde-tierras-la-legitimaciondel-despojo/426585-3; https://pbicolombiablog.org/2018/01/05/ la-oscura-historia-deldespojo/; http://www. contagioradio.com/ las-11-empresas-que-seoponen-a-la-restitucionde-tierras-segun-estudiode-forjando-futuros-articulo-22580/

\section{territorias 42-Especial}

de las armas, las amenazas, los asesinatos y la construcción de laboratorios para transformar la hoja de coca.

Aunque la unificación paramilitar permitió ejercer control con mayor eficacia, la masacre de San Carlos de Guaroa ${ }^{2}$ rompió dicha alianza. Se inició una disputa por el territorio que se tradujo en extorsión a los propietarios que seguían en las veredas y matanza de dirigentes políticos y líderes comunitarios en municipios aledaños $^{3}$ (Fundación Puerto Rastrojo, 2014). Quienes no huyeron de las veredas, se vieron obligados a pagarle vacunas a los frentes paramilitares en especie (10 reses, cobraba Buitrago), o en dinero (\$7 000000 cop cobraba “Cuchillo"). En algunos casos, familias enteras quedaron en medio de combates durante sus recorridos por el hato o se vieron obligados a entregar sus vehículos a los paramilitares, quienes usando la presión de las armas también se tomaban las casas a su antojo.

La guerra en La Serranía duró 8 meses; se dice que murieron más de 3000 hombres. De acuerdo con el testimonio del narcotraficante Daniel Rendón Herrera, Víctor Carranza sería uno de los responsables de esta confrontación, pues “Carranza habló con Miguel (Arroyave) sobre Martín (Llanos), y ahí me di cuenta de que Miguel se dejó utilizar, para indisponerlo con Martín. Pienso que hizo lo mismo con Martín" (Verdad Abierta, 2009). Esta guerra fue ganada por los Urabeños, presuntamente con el apoyo de las fuerzas militares. En 2004, La Serranía pasó a ser controlada por "Cuchillo", quien ordenó asesinar a Miguel Arroyave. Así, "Cuchillo" logró quedarse con el control de las rutas del narcotráfico en Meta, Guaviare y Vichada. En 2005 "Jorge Pirata" se acogió a la Ley de Justicia y Paz y "Cuchillo", a pesar de entregar municiones y armamento, continuó sus acciones armadas fundando el Ejército Revolucionario Popular Anticomunista (ERPAC) (Verdad Abierta, 2008).

\section{Agronegocio y extractivismo: un llano sin llaneros (2005-2018)}

Una mirada al mapa de la violencia ejercida por paramilitares en Colombia evidencia la coincidencia con el mapa de expansión minero-energética, agroindustria y del control de las mejores tierras productivas. Numerosos estudios han demostrado que emporios agroindustriales se beneficiaron del despojo cometido por paramilitares. ${ }^{4}$ En zonas como el Urabá, Magdalena Medio y los Llanos Orientales, los desplazamientos masivos e incluso las masacres, permitieron construir espacios de miedo para facilitar la acumulación de tierras para el desarrollo de proyectos agroindustriales. La estrategia de control territorial mediante la expansión de cultivos como la palma ha sido promovida por los últimos 4 gobiernos con el pretexto de hacer más competitivo, a nivel internacional, el campo colombiano. Así, estrategias como la adjudicación de baldíos de la nación a grandes empresas multinacionales se 
basa en el principio desarrollista de la competencia productiva. ${ }^{5}$ Las políticas rurales se han enfocado en disminuir la diferencia de competitividad frente a otros países, sin atacar la inequitativa estructura en la tenencia de la tierra, en muchos casos consolidada mediante la expansión paramilitar. ${ }^{6}$

El enfoque de desarrollo rural basado en el monocultivo de productos como la palma y los maderables es una de las propuestas del Banco Interamericano de Desarrollo (BID) que el gobierno colombiano ha acogido. Al respecto, el criterio del BID acerca de los cultivos de mediano y largo plazo - como los mencionadoses que tienen mayor potencial exportador y capacidad de supervivencia en una economía liberalizada y permiten control territorial. Resulta indispensable centrarse en la última característica que el BID resalta de dichos cultivos (Sandoval, 2015).

Esta concepción del control territorial a largo plazo, a través del uso de plantaciones que pueden tener un reintegro productivo de hasta treinta años, responde a una visión del desarrollo economicista y de competencia a nivel internacional que genera transformaciones espaciales. Si bien existe fuerte presencia de maderables en la vereda La Cristalina, la palma es indudablemente una amenaza latente para ambas veredas. Como se puede analizar a partir de la figura 4 , las principales presiones ambientales y alternativas de transformación en los sistemas económicos veredales

Figura 4. Plantaciones de palma y maderables en las veredas

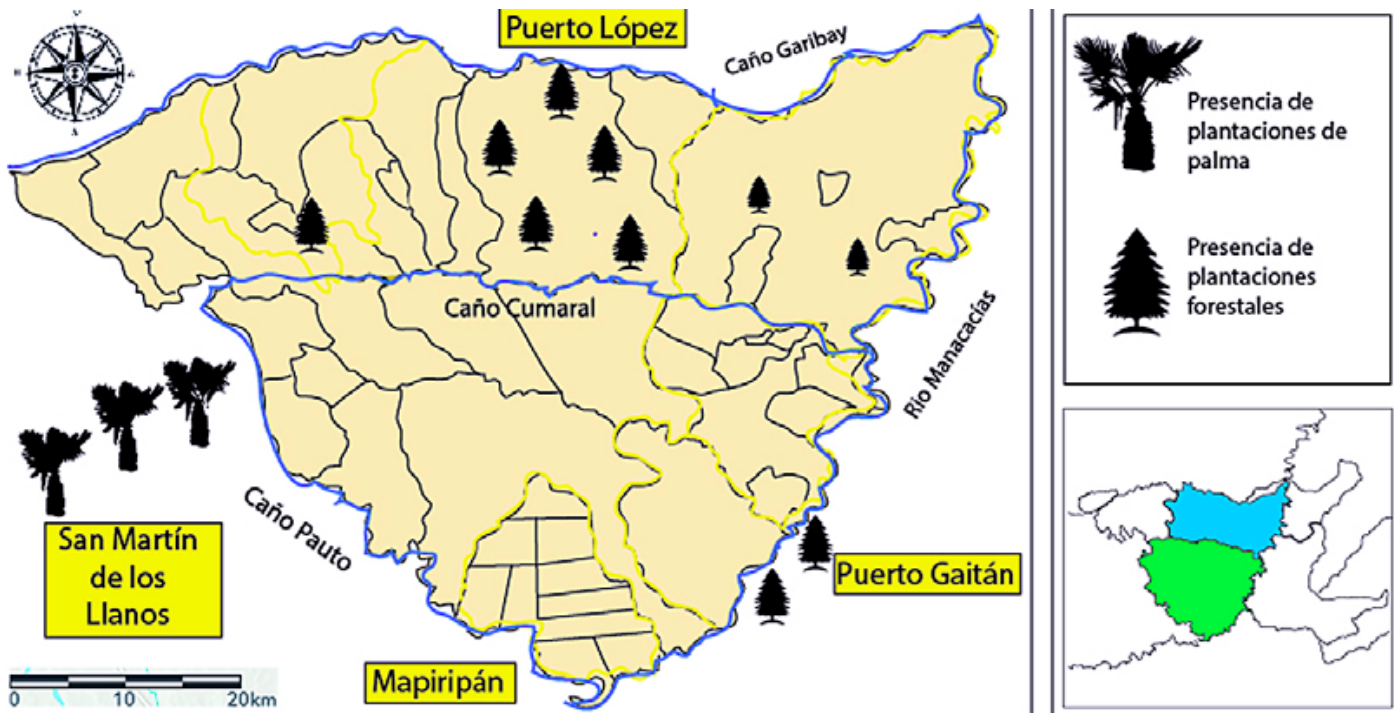

Apropiación del espacio en La Serranía de Manacacías, Orinoquía colombiana

5 Ver: Ley 1776 del 29 de enero de 2016. http:// es.presidencia.gov.co/ normativa/normativa/LEY\%2 $01776 \% 20$ DEL\%2029\%20DE\%20 ENERO\%20DE\%202016. pdf

- Según el Instituto Geográfico Agustin Codazzi, el indice de gini rural es aproximadamente 0.87. https://www.eltiempo.com/economia/ sectores/desigualdad-enla-propiedad-de-la-tierraen-colombia-32186

\section{territarios 42-Especial}




\section{tersitorias} 42-Especial están dadas por las plantaciones de palma africana y cultivos forestales.

El control mediante cultivos de palma puede analizarse con mayor profundidad en el libro La economía de los paramilitares, escrito por Ariel Ávila (2011). En él, se afirma que el proyecto palmero se constituyó en un eje articulador de grandes empresarios rurales con fracciones paramilitares que habían implementado la estrategia de tierra arrasada. De igual manera, Carlos Medina Gallego (2005) destaca que las investigaciones adelantadas por las autoridades competentes han arrojado como resultado "extensos listados de comerciantes, industrias prestigiosas, empresas transportadoras, entidades bancarias [y] empresas cooperativas de productores, [que] indican la diversidad de las fuentes de financiación y la complejidad de la economía de tributación de la guerra paramilitar" (Medina Gallego, 2005, p. 82). La introducción de cultivos maderables en la zona ha despertado en los pobladores opiniones diversas. Mientras algunos ven en estas iniciativas una alternativa posible de empleo o de inversión, otros no están conformes con su implementación. Luis Rodríguez afirma que "es mejor que se reforeste con especies nativas como el cañafistol, el cedro grillo y el laurel, debido a que las especies foráneas alteran la calidad del suelo" (Fundación Puerto Rastrojo, 2014 , p. 35). Aunque algunos consideran como alternativa rentable el cultivo de estos productos, la disminución de la ganadería y la transformación de la actividad productiva ha reemplazado la actividad ganadera; quienes en algún momento fueron vaqueros, son trabajadores intermitentes de las plantaciones y los hombres y mujeres dedicados al trabajo llanero han ido desapareciendo paulatinamente.

Además de la presencia de las compañías forestales y de la agroindustria, dentro y alrededor de las veredas, varias compañías petroleras han realizado exploración y explotación de hidrocarburos. En la vereda Puerto Castro, Ecopetrol ha intervenido con exploración sísmica en los bloques CPO-11 y Caño Sur, dejando pozos que ya han sido abandonados. En esta misma vereda, la empresa Petrominerales tuvo el bloque Chigüiro, el cual abandonó en 2009. En la actualidad existe un bloque petrolero disponible en las veredas Puerto Castro y La Cristalina. En el área existían seis bloques, de los cuales cuatro desistieron porque no encontraron crudo. "Quedaron 2 que en el fondo creo que son de Ecopetrol, han venido cambiando de dueño, Upecol y Frontera Energy son los dueños" (Hernández, comunicación personal, 2018).

Aunque la exploración de hidrocarburos se remonta a la década de 1952 , fue principalmente en 2006 que se hicieron las primeras perforaciones en las fincas El Encanto y Santa Teresita. La presencia de las compañías petroleras se intensificó desde el año 2008, lo que coincide con el declive de la presencia de los paramilitares en la zona. Las implicaciones ambientales de la introducción de los nuevos sistemas 
representan una amenaza al equilibrio ecosistémico de La Serranía. En términos ambientales, esta cuenta con gran potencial hídrico, pues el paisaje ha permitido la acumulación de pequeños pozos de agua en las bases de las cadenas de lomeríos. Estos espacios son identificados por los pobladores y por instituciones de conservación como PNN como lugares de abastecimiento de alimento y agua para animales como el chigüiro, la danta, el oso palmero, el venado, el cafuche, el saíno y el armadillo, entre otros.

De igual manera, la gran cantidad de flora hace de La Serranía un lugar con una riqueza biótica incalculable. Estudios recientes de Cormacarena (2014) encontraron un total de "868 especies de flora, pertenecientes a 407 géneros y 104 familias, con posible ocurrencia en el área de estudio. Las familias más ricas en especies son Poaceae, Fabaceae, Rubiaceae y Cyperaceae, con más de 60 especies cada una" (p. 26). A su vez, se identificaron 220 especies de aves, 33 especies de reptiles, 95 especies de mamíferos, 25 especies de anfibios y 300 especies de peces (Cormacarena, 2014). Este panorama ambiental ha hecho de La Serranía un lugar priorizado para su conservación. A mediados de 2016 se iniciaron las socializaciones del Proyecto Alto Manacacías con los propietarios de las veredas Puerto Castro y La Cristalina.

A pesar de que el proyecto declaratorio del nuevo Parque Serranía de Manacacías llegó hasta la fase de delimitación del polígono, el proceso no siguió en curso. Los recursos necesarios para la compra de 78000 ha, área que finalmente se definió para su conservación, no lograron ser captados. De acuerdo a versiones de miembros del equipo de PNN, el principal rubro a utilizar para la compra de los predios era producto de la Ley 99 de 1993, ${ }^{7}$ que exigía la destinación del $1 \%$ del total de la inversión de proyectos que requirieran licencias ambientales para la recuperación y preservación de áreas de interés ambiental. Dicho rubro no pudo ser utilizado. Algunas conversaciones fuera de grabación recalcan que el cambio de gobierno influyó en la decisión de las petroleras de no invertir el $1 \%$ en la declaración de la nueva área protegida. Si bien estas actividades en La Serranía son relativamente recientes, las lógicas de desarrollo dirigidas desde las distintas presidencias han visto en la Orinoquía un territorio con grandes aptitudes para la agroindustria y la explotación de hidrocarburos. Esta situación ha provocado transformaciones espaciales que van desde la ruptura de la identidad, hasta la conversión de los llaneros en trabajadores de las plantaciones. A su vez, la disputa por la apropiación de los predios entre instituciones públicas y organizaciones privadas se convirtió en la situación actual de las veredas Puerto Castro y La Cristalina.

\section{Resultados}

Los resultados obtenidos a partir de las entrevistas y el trabajo de campo realizado
7 Ver: http://www.minambiente.gov.co/images/normativa/app/decretos/b6-decreto-2099. pdf 
${ }^{8}$ Comida a base de yuca y maiz.

${ }^{9}$ Guías.

\section{territarias}

42-Especial dan cuenta de las transformaciones sufridas en las veredas a partir de las distintas apropiaciones espaciales de estas.

\section{La ganadería: base para la nueva organización social de Puerto Castro}

Sin lugar a duda, uno de los primeros resultados encontrados en este acercamiento inicial es el de los procesos de desplazamiento producto de la violencia y posterior búsqueda de tierras para trabajar. El proceso de colonización a través de la ganadería desconoció que en las veredas ya existían habitantes: los guahibos. Frente a las emergentes relaciones con ellos, Gildardo Rey destaca que eran tribus pequeñas de no más de 30 personas, quienes vivían de la caza, la pesca y el mañoco: ${ }^{8}$

Mi papá tuvo un indio de trabajador, Valentín, y él era el mensual, aprendió a montar caballo. Con los indígenas era una relación de trueque o a veces se les pagaba con dinero o en especie, con herramientas, ropa y a las mujeres con labiales (Rey, comunicación personal, 2018).

La apropiación del espacio a través de la ganadería no solo significó una nueva representación del espacio rural de las veredas, sino que la propiedad privada y la actividad productiva definió una nueva organización social. Muchos indígenas fueron asesinados y otros tantos decidieron salir por su cuenta, al ver que el acceso a los recursos ubicados en las veredas comenzaba a ser privatizado y limitado por los colonos. A su vez, la utilización de los indígenas como baquianos ${ }^{9}$ y su transformación en trabajadores rurales permitió que los colonos se apropiaran de la técnica de techado de palma, propia de los indígenas. De igual manera, el consumo de mañoco se fue conociendo entre los nuevos fundadores de propiedades. De acuerdo con versiones locales, tres años después de la fundación de Hato Palmeras, de propiedad de Alejandrino Rey, padre de Gildardo Rey, la familia de indígenas que habitaba la zona desmontó su rancho y se fue para siempre: "la ida de los indígenas se debió a que el ganado que recién llegaba se comía los cultivos de los indígenas" (Rey, comunicación personal, 2018).

Ramiro Hernández, hijo de uno de los primeros colonos de la vereda Puerto Castro, destaca que el Hato Civira fue fundado hacia los años 50 luego de la conformación de la Junta Militar:

Mi papá y mis tíos tuvieron que salir de San Martín y de donde ellos tenían la finca de mi abuelo, en Surimena, en San Carlos de Guaroa. Salieron abruptamente y recogieron su ganado, vendieron la finca del abuelo y el ganado lo llevaron acá a La Serranía a donde un paisano, el ganado lo dejaron botado, luego cuando mi papá volvió del Chocó de trabajar, fundó Hato Civira (Hernández, comunicación personal, 2015). 
El efecto llamada mencionado en apartados anteriores, resulta determinante para los procesos de poblamiento tanto para Puerto Castro, como para La Cristalina, con diferencias relativamente pequeñas. Gildardo Rey (2018), hijo de uno de los fundadores de la vereda, destaca que luego de la antigua violencia, ${ }^{10}$ La Serranía comenzó a repoblarse con ganaderos y campesinos en efecto dominó:

Los veteranos de esa violencia comenzaron a colonizar, entraban familias, entraba el uno, y luego el otro, ahí El Diamante era de unos señores Rufino y Fernando, familiares de mi papá y le dijeron que había unas hectáreas disponibles, mi papá se fue, era el año 55, yo tenía 7 años. El primer viaje no estuve, entraban en carro hasta un punto y luego a lomo de caballo o mula, luego don Fernando le dijo a Alejandrino, mi papá, que cogiera esas hectáreas, eran como 6000 (Rey, comunicación personal, 2018).

El hecho de que la colonización se diera en efecto dominó significó la consolidación de los hatos como nodos de una red a través de la cual circulaba información entre los miembros conectados a la misma (colonos y familiares de colonos). Esta característica favoreció la toma de decisiones respecto al traslado a La Serranía, al tiempo que disminuyó la incertidumbre de los nuevos colonos, quienes sabían de antemano a dónde iban y con qué se encontrarían. Con la ganadería, inició una nueva organización social.
La jerarquización espacial resultó de la priorización de la ganadería sobre la actividad agrícola de los indígenas. Los hatos, además de servir como punto de partida para los nuevos colonos, se convirtieron en el núcleo central de las relaciones sociales y económicas. Se definieron roles basados en la ganadería y la división social del trabajo de la siguiente manera:

El encargado es el que manda en la finca, cuida el ganado, los caballos, está atento de la casa, limpiar la corraleja, los marranos, todo, en algunos lados los llaman administrador. Hay uno que se le tiene el nombre de mensual que es el que le ayuda al encargado para que no salga solo a la sabana, a hacer los oficios, el encargado tiene esposa y tiene un mando mayor, allá cuando no están los patrones el encargado queda al mando. El caporal es la persona que cuando se saca ganado a caballo, manda a los vaqueros, ordena a los vaqueros y cuenta el ganado 2-3 veces al día (Rey, comunicación personal, 2018).

Aunque se podría pensar que gran parte de los Llanos Orientales posee tierras fértiles y aptas para la actividad agrícola, no es así en La Serranía. La calidad del suelo no tiene las condiciones para producir lo suficiente sin un trabajo previo de adecuación de la tierra, fertilización con insumos químicos y abonos. Cuando se transita por las veredas en época de invierno, las trochas se pintan de rojo debido al alto nivel de hierro del suelo.
${ }^{10}$ Término que utilizan algunos colonos para referirse al periodo comprendido entre 1948 y 1953. 
De hecho, una plantación de maracuyá ubicada a pocos kilómetros de las veredas en estudio no dio la producción esperada, aproximadamente 400 plantas de dicha fruta se marchitaron.

Esta es la razón más importante por la que Puerto Castro y La Cristalina son veredas ganaderas. Roberto Aya explica:

acá eso sembrar no pega, ahorita están ensayando con yuca, pero quien sabe. Para comer es con la remesa y carne de monte, a veces, chigüiro, lapa, cafuche, saíno, venado. Pero yo no mato cafuche ni venado ni danta, eso me da pecado matarlos (Aya, comunicación personal, 2015).

\section{La parcelación de Cejalito: "una verdadera reforma agraria"}

Aunque se desconocen los primeros propietarios, en La Cristalina el hito fundacional se remonta al Hato Cejalito y a Ishido Kawai. Cejalito fue tal vez el hato que más ganadería tuvo al occidente del río Manacacías: llegó a contar 12000 reses, por todo el bajo del Melúa.

Luego, los japoneses metieron 14000 reses. Yo era vaquero, he trabajado acá desde siempre, en Tamaco, Caribe, de vaquero. Yo trabajé con Tulio Ossa, yo soy del Casanare, mi familia vivía en las costas del Pauto, por parte de mi mamá soy indio (Marchena, comunicación personal, 2015).
La situación en La Cristalina, aunque un poco distinta a la de Puerto Castro, tuvo el mismo inicio de colonización y poblamiento. Luego de que Kawai fuera capturado, Hato Cejalito fue parcelado. El efecto llamada de los trabajadores de Kawai no se hizo esperar. En la figura 5 se puede detallar de mejor manera el proceso fundacional de los hatos de ambas veredas, a partir de migraciones de campesinos sin tierra y de jornaleros en busca de sustento:

Estos señores se encartan con esa hacienda, entonces duraron tal vez 3 o 4 años bregando a cubrir y a cumplir y en un momento dado, el hato se va despoblando de ganado y comienzan a fundarse personas en las riberas (...) Entonces se reúnen varias personas mirando cómo se iban a dar las cosas y en el mes de agosto de 1984 nos repartieron la tierra con el mapa, y empieza la gente a fundar (Sierra, 2014, en Fundación Puerto Rastrojo, 2014).

Jesús Sierra, destaca que:

Los súbditos como ya no tenían cómo explotar la finca, tenían escuela, zoológico, una serie de cosas como para que no se abandonara esto, entonces llamaron a la gente para que cogieran tierra, entonces yo no sé, eso es poco común, pero no tenían los recursos para manejar esto (Sierra, comunicación personal, 2017). 


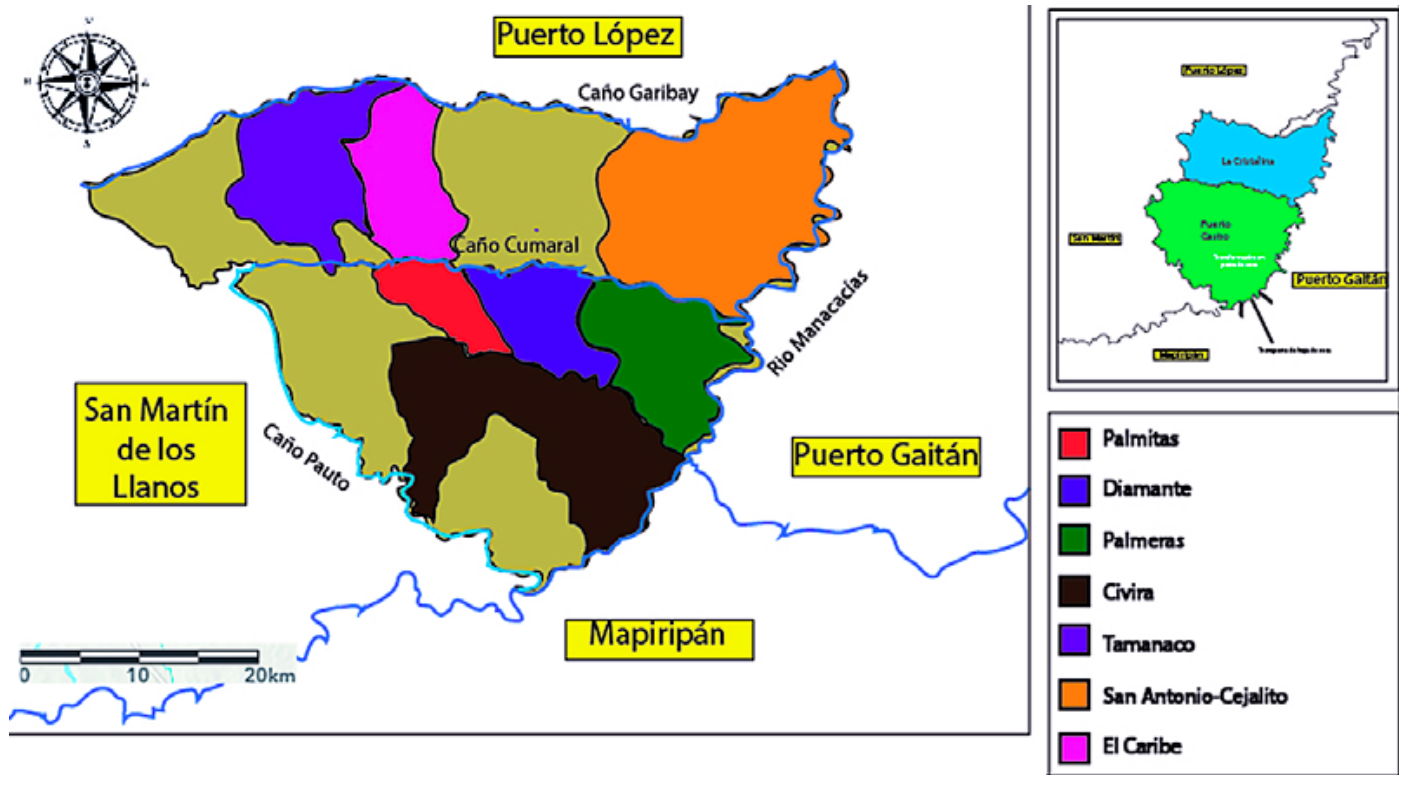

Fuente: Adaptado de Parques Nacionales Naturales (2017).

La parcelación de Cejalito definió una estructura en la tenencia de la tierra de fundos sin títulos de no más de 2000 ha. A su vez, promovió la transformación de la estructura social patronal que tenía en Kawai la cabeza. Además, generó cambios en las concepciones territoriales y espaciales de los nuevos propietarios. Estos, junto con los antiguos trabajadores, confluyeron en la transformación de la estructura social producto de la repartición de predios. Sobre este hecho, Jhon y Jesús Sierra afirmaron: "fue una verdadera reforma agraria en estas tierras" (Sierra, comunicación personal, 2017). Aunque algunos de los antiguos trabajadores se convirtieron en propietarios, la calidad del suelo obligó a una gran cantidad a vender sus parcelas. Este mercado de tierras atrajo nuevos propietarios de Villavicencio y Bogotá, quienes reactivaron la ganadería a gran escala y acumularon parcelas.

Aquí hay historias interesantes, una finca se la dieron al guahibo Alberto y como a los dos años lo cambió por 6 vacas porque esto no valía nada. Una persona que tuvimos acá hace rato, mayordomo de mi hermano, él no quiso tomar tierra porque no tenía cómo producir, Don Mario que vive al lado de La Cristalina que trabajaba con los japoneses, los japoneses quisieron darle tersitarios 42-Especial 
${ }^{11}$ Se codifica el nombre del Entrevistado para proteger su identidad.

12 Vebiculo de Flota La Macarena.

\section{territarias 42-Especial} 18 tierra a algunos, pero solo uno tomó tierra, el morado Misael, el de San Jorge, los otros 45 no aceptaron porque pa' qué tierra si no había plata para ponerla a producir (Sierra, comunicación personal, 2017).

\section{Control paramilitar e ingreso del narcotráfico: nueva apropiación espacial}

Ya se ha mencionado que cuando los paramilitares ingresaron a La Serranía lo hicieron fundando dos grandes caseríos: El Tropezón y La Jungla. Este hecho representa una transformación en la forma de apropiación espacial. Se pasó de la ganadería en la época de la colonización hacia los años 60 y 70, al control territorial a través de la fuerza. El Entrevistado $\mathrm{H}^{11}$ resalta que en esa época "La Jungla que es un bordito que da a Mapiripán, era más grande que Tropezón, puras casas de madera y ellos hicieron discotecas, almacenes, graneros, de todo, ropa, zapatos, encontraba lo que quisiera" (Entrevistado $\mathrm{H}$, comunicación personal, 2018). El control territorial de los paramilitares era de tal envergadura, que quienes entraban a La Serranía debían ser recomendados o conocer a algún habitante de la zona, “alguien tenía que recomendarlo, alguien de por acá, hubo gente que no salió. La gente que llegaba y no era recomendada ahí quedaba y hasta luego" (Entrevistado $\mathrm{H}$, comunicación personal, 2018). Además de "Los Buitragueños", los miembros del MAS liderados por alias "Samurai" se apropiaron del espacio llanero de La Serranía. De hecho, la vereda Puerto Castro recibe su nombre por un atroz asesinato cometido por miembros del MAS:

Cuando eso no habían (sic) paracos, estaban los masetos, armados hasta el culo, hijueputa, cuando vino Castaño entraron los paracos, cuando la escuela en Civira, yo hice entrenamiento ahí y allá. Yo hice entrenamiento con los paracos con un cabo del ejército, a ese man de los masetos lo mataron en Casanare, ese fue el que mató el planchonero de La Jungla y al hijo, y la vereda se llama así, por eso, porque de allá [Mapiripán] se vino la guerrilla y se trajeron el bus, bajaron allá y yo estaba en Civira, y yo dije ¿una Macarena ${ }^{[12]}$ por acá? Y eso se mira bien por allá, la carretera por La Gloria. El tipo era "Samurai", era un loco de los locos, encendió el planchón, mato los manes, volvió mierda todo. "Samurai" mató al planchonero, Gustavo Castro, y al hijo, fue muy terrible, eso no lo hace sino ese loco, esa muerte solo la hace ese hijueputa loco. ¿Cómo va a matar al señor? ¿Cómo iban a tener la culpa si ellos estaban armados? (Entrevistado H, comunicación personal, 2018).

El Hato Civira, que menciona el Entrevistado $\mathrm{H}$ como lugar de entrenamiento conjunto entre paramilitares y el ejército, fue dividido en dos. Ramiro Hernández, heredero del Hato Civira de los Mohos, describe esta situación de la siguiente manera: 
La otra Civira, lo que hoy es Planas o Planadas, mi papá y mi tío se la vendieron a don Héctor Buitrago. A Buitrago lo sacaron en la guerra de ellos, don Héctor estaba en guerra con Arroyave, Buitrago estaba con Pirata y a los Arroyave los apoyaron los del ejército, y Buitrago salió huyendo, eso fue una cosa impresionante (Hernández, comunicación personal, 2015).

El hato conocido hoy como Planadas fue vendido por los dueños originales producto de presiones de los paramilitares de Héctor Buitrago, pues su fin último era controlar la mayor cantidad de territorios para potenciar la actividad productiva que venía en aumento: la transformación de la hoja de coca. Sumado a esto, nuevas relaciones sociales comenzaron a establecerse entre los actores armados y los pobladores, muchos de los cuales tuvieron que huir. El despojo se configuró como herramienta de apropiación espacial de los actores armados presentes en la zona. Además, la unificación paramilitar en el Bloque Centauros permitió centralizar el poder y el control social, económico y espacial.

Ernesto Rey, hermano de Gildardo Rey, afirma que mucha gente se desplazó, pues los paramilitares "hacían lo que querían por acá, mataban al que fuera, como estaban armados... el propósito era dominio del territorio por el pasadero de la coca, se votaban en planchones, salían a Puerto Gaitán" (Rey, comunicación personal, 2015). El hecho de que muchos de los dueños y administradores tuvieran que salir del territorio significó una reconfiguración espacial que impactó la estructura social heredada de la colonización y la ganadería. Los hatos desocupados fueron acumulados por los comandantes de las estructuras paramilitares. Si antes la apropiación espacial estaba dada a partir de la ganadería, los paramilitares se apropiaron de La Serranía a través del despojo, la expansión armada y la introducción de trabajadores para las cocinas de transformación de la hoja de coca, quienes invadieron algunos predios. En la figura 6 se identifican las mencionadas cocinas para la transformación de hoja de coca que estaban ubicadas estratégicamente para poder enviar la pasta de coca de forma rápida y recibir insumos para continuar con el proceso.

Ramiro Hernández confirma la versión de Ernesto Rey:

a ellos les importaba los territorios para tener las cocinas de coca, no eran cultivos, los cultivos los traían de Mapiripán y Guaviare, acá solo eran cocinas, en toda La Serranía habían cocinas, por todo lado ellos tenían gente de ellos (Hernández, comunicación personal, 2015).

Roberto Aya, quien vivió en La Serranía durante 50 años respalda a Ernesto Rey y a Ramiro Hernández: "era para controlar las cocinas, coca no sembraban, por acá era el paso del narcotráfico" (Aya, comunicación personal, 2015). territarios 42-Especial 
Figura 6. Ubicación de los laboratorios para transformar la hoja de coca

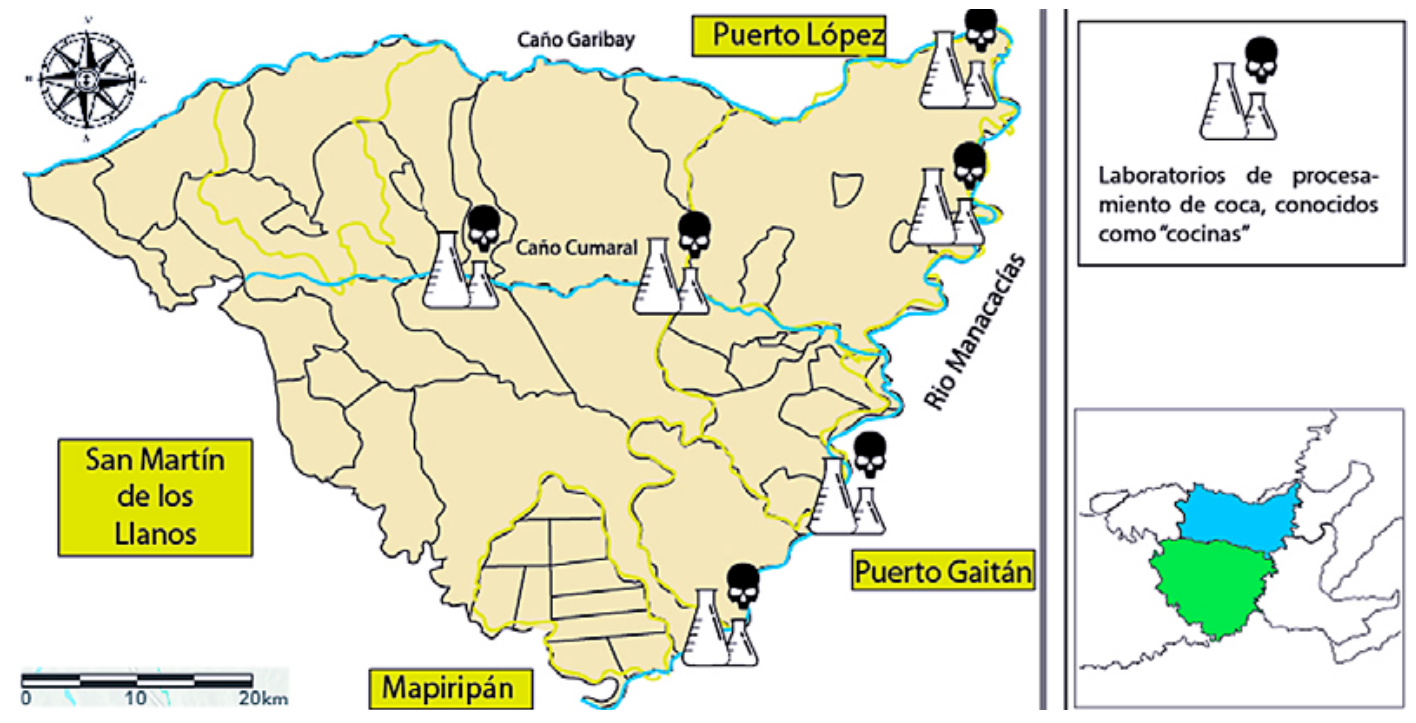

Fuente: elaboración propia (2018).

Este amplio dominio territorial tenía dos funciones: en primer lugar, permitía un escondite de objetos y seres humanos. "Entre las diversas cosas que se pueden esconder están: cuerpos humanos (cadáveres, personas torturadas, secuestrados), objetos robados, armas, pistas de aterrizaje, laboratorios y otra infraestructura para economías ilegales" (Gutiérrez Sanín, 2014, p. 51). En segundo lugar, se convirtió en el espacio de planeación de operaciones militares, además de consolidarse como campo de entrenamiento donde se contaba con apoyo militar oficial. A partir de las versiones de algunos entrevistados, en la figura 7 se evidencia el amplio despliegue paramilitar y su control veredal a partir de campamentos, campos de entrenamiento y pistas para la entrada y salida de insumos de guerra, droga y, en algunos casos, tropas.

El despojo de tierras y el desplazamiento de propietarios reforzaron las formas de apropiación del espacio llanero por parte de los paramilitares y las maneras de concebir el territorio por parte de los colonos. Autores como Fajardo (2002), Zuluaga (2002) e Ibáñez y Querubín (2004) afirman que el desplazamiento forzado no es una casualidad. La expulsión de la población y la estrategia de tierra arrasada es una herramienta para la guerra misma. Se busca intimidar a los pobladores, apropiarse de las tierras e inclusive abaratarlas para fomentar un nuevo mercado de ellas: "el método principal para influir en el precio y las cantidades de equilibrio en el mercado de tierras es 
Figura 7. Presencia paramilitar en La Serranía

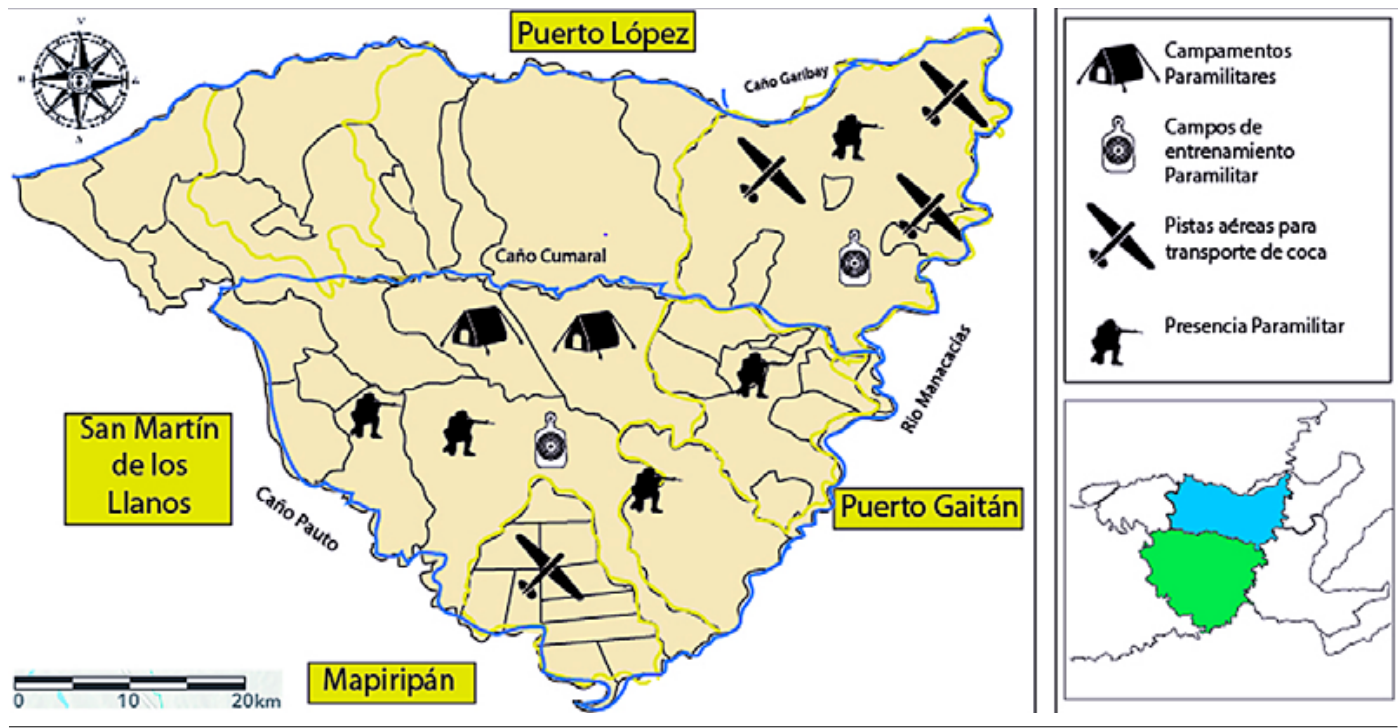

Fuente: elaboración propia (2018).

el desplazamiento forzado" (Rey Sabogal, 2013, p. 689).

El control de lugares a los que no se podía ingresar, el establecimiento de horarios para poder movilizarse en el territorio, las restricciones para la caza y la pesca, la inspección de quienes ingresaban a las veredas y el amedrentamiento se convirtieron paulatinamente en mecanismos de despojo y en características que transformaron en espacio de miedo a La Serranía. Una característica particular de este periodo histórico y del proceso de apropiación espacial por parte de los paramilitares fue la disminución de la ganadería. Numerosas investigaciones han demostrado la simbiosis entre expansión paramilitar y ganadería (Vergara, 2010;
Vega Cantor, 2012; Gutiérrez Sanín, 2015; García Pérez, 2016), mas en el caso abordado se evidenció todo lo contrario. De acuerdo a conversaciones fuera de grabación, muchos hatos que inicialmente contaban con 4000 cabezas de ganado, pasaron a tener 400 o 500. Las razones que dan quienes mencionaron esta característica son

1. Muchos jefes paramilitares cobraban las extorsiones en cabezas de ganado para venderlas en San Martín y Puerto López.

2. Los paramilitares se alimentaban de las reses, un contingente de 200 hombres podía consumir entre 5 y 7 reses mensualmente. tersitarios 42-Especial 
3. El costo de esta actividad económica aumentó: los insumos para 300 cabezas de ganado podían llegar a los 70 millones de pesos.

4. Muchos de los nuevos propietarios, hijos de los primeros colonos, decidieron no inyectarle más capital a las propiedades y dejarlas con pocas cabezas de ganado.

Desde luego, el análisis estadístico para reforzar las afirmaciones hechas, es una tarea pendiente.

\section{Agroindustria y venta de propiedades: desocupación de las veredas}

El declive de la actividad ganadera, la desocupación de hatos y el control territorial paramilitar provocaron una ruptura identitaria de los herederos con el espacio llanero de las veredas y transformaron las representaciones sobre el territorio. Los hatos se convirtieron, en muchos casos, en una carga para los propietarios. Los costos de insumos para el pasto y de medicamentos para el ganado, sumados a la dificultad para encontrar administradores que fueran constantes, la distancia y la relativa dificultad para ingresar a las veredas abonaron un escenario apto para que emporios agroindustriales y de hidrocarburos se beneficiaran de la urgencia de vender los predios. Las investigaciones realizadas por Díaz (2016) y Rodríguez (2014), también en los llanos orientales, así como el análisis de Rey Sabogal (2013), permiten evidenciar que existe una generalidad entre el avance de la agroindustria palmera y las zonas de despojo y violencia.

Esto ha generado no solo graves afectaciones ambientales y territoriales a gran escala, sino que ha permitido a las empresas acumular tierras, ha transformado la vocación del uso del suelo y características socioculturales propias del vaquero llanero, quien ahora trabaja en las instalaciones petroleras o en las plantaciones de palma, acacia o pino.

Edimer Hernández, funcionario de PNN de Colombia, destaca que "la mayoría quiere vender, además porque montar un sistema productivo es muy difícil, muy costoso, y aunque algunas personas quieran montar un sistema productivo es bastante costoso" (Hernández, comunicación personal, 2018). En la medida en que muchos de los nuevos propietarios han relacionado al hato como una carga, la calidad de vida de los administradores ha disminuido, lo que ha producido inestabilidad de los mismos en la vereda. En tanto existe esa concepción del hato, los nuevos herederos no se empeñan en mantener unas condiciones dignas para los administradores, quienes en algunos casos se han visto obligados a cazar para poder comer, como el Entrevistado $\mathrm{H}$ :

Los hijos de uno aguantan hambre en el pueblo, no me lo pregunta, pero hoy en día mis hijos aguantan hambre porque yo no alcanzo a mandarles para hacerles un mercado 
allá, si yo hago el mercado acá lo poquito que me queda me toca mandarles (Entrevistado $H$, comunicación personal, 2018).

Además, las nuevas tecnologías, la distancia entre el pueblo y las veredas, así como los nuevos proyectos personales han hecho de la tarea de encontrar administrador para los hatos, un proceso difícil. Así, en la medida en que no existen trabajadores capacitados en la administración de los predios, la venta de estos se vuelve más urgente. Por ejemplo, hacia principios de febrero de 2018, se realizó una visita de campo a la vereda Puerto Castro. Una de las cuatro mujeres habitantes de la vereda, de aproximadamente 20 años, tomó la decisión de volver al pueblo, argumentando que le resultó complejo adaptarse a la vida del campo, más al estar a 8 horas del casco urbano. En la última salida de campo, que se realizó a mediados de abril de 2018 , se constató que la distancia es un aspecto crítico para la adaptación de las parejas jóvenes al contexto. La compañera del administrador de Hato Diamante, en la vereda Puerto Castro, decidió salir del predio con su hijo de 3 años producto de una enfermedad gástrica del menor. Ante la imposibilidad de conseguir personal médico en la vereda, la mujer tomó la decisión de volver a radicarse en el pueblo.

En este escenario, han incursionado nuevos actores, especialmente en la vereda La Cristalina, a implementar cultivos forestales. En ella hacen presencia Campo Forestal y Plantaciones El Encanto. La primera es una empresa que administra la finca El Porvenir de 17000 ha, propiedad de Cumare s.A., donde operan tres empresas forestadoras: Reforiente, Refocosta y el grupo Valt, las cuales tienen proyectado sembrar 16000 ha en total de árboles maderables, en su mayoría de Acacia mangnum.

Woods (2009) afirma que la nueva geografía en torno al campo globalizado hace parte de una profunda red de interconexión y vinculación con su entorno y el urbano. A partir de esta idea, plantea el concepto de campo global, en contraposición a la idea de la ciudad global, bajo la que se ha desarrollado ampliamente la cuestión de las expresiones territoriales de la globalización. Así, el campo global es un espacio hipotético que corresponde a una condición de interconectividad global e interdependencia entre las localidades rurales (Ávila Sánchez, 2015, p. 82).

Plantaciones El Encanto, por su parte, es un proyecto de 3000 ha, ubicado en la vereda Puerto Castro. Allí se han sembrado 1200 ha de Acacia mangnum, y se tiene proyectado sembrar otras 800 . Esta plantación en específico se ha financiado mediante el mercado de bonos de carbono, "hasta que se empiece a sacar madera once años después de las primeras siembras" (Fundación Puerto Rastrojo, 2014, p. 24). La llegada de estas iniciativas a la zona ha generado que en varias fincas de La Cristalina y de Puerto Castro otros comiencen a sembrar pequeños cultivos de árboles maderables. Edimer Hernández ha territarios 42-Especial 


\section{tersitorias} 42-Especial observado que el eucalipto lo siembran en las pares bajas, cerca de fuentes de agua; la parte libre, lo que eran los lomeríos, está siendo ocupada con pino, el cual se da muy bien en las lomas. Se está acabando con lo poquito que quedaba de la biodiversidad, un estudio de la Universidad Nacional sobre aves de 2014, identificó 450 especies de aves antes del cultivo. Luego de este encontraron 40 especies nada más, el impacto es considerable (Hernández, comunicación personal, 2018).

A partir de información suministrada por propietarios de la vereda Puerto Castro, se logró conocer que empresarios holandeses pretenden comprar 20000 ha para iniciar el cultivo de árboles maderables. Sin embargo, lo que ha detenido la compra de los predios es el tema de titulación, pues la mayoría de hatos no cuentan con los documentos necesarios para dicha transacción: "eso ha sido un punto a favor para evitar esa enajenación de tierras... ha sido esa demora del catastro rural (sic)" (Hernández, comunicación personal, 2018).

Hernández también afirma que luego de la Resolución 1628 se inició el estudio preliminar con 242000 ha de La Serranía, en las cuales se identificó que la mayor parte de paisaje transformado se encontraba en la vereda La Cristalina. Por esta razón, el interés de PNN se concentró en la vereda Puerto Castro. El autor de esta investigación tuvo la oportunidad de asistir a algunas de las socializaciones realizadas en San Martín, en las que evidenció la gran preocupación de los propietarios en términos prediales. La mayoría consideraba peligroso el ingreso de una institución como PNN, pues se corrió el rumor de que serían víctimas de expropiación. La incursión de este nuevo actor significó una disputa por la compra de los predios. Se trataba de ganarle el pulso a la agroindustria y a las petroleras con un fin conservacionista. Algunos propietarios se mostraron abiertos al diálogo con la institución; sin embargo, muchos criticaron el hecho de que la presencia estatal se diera tan tarde. Además, recalcaban que los mismos pobladores eran protectores del medio ambiente, pues realizaban quemas para la mejora de los pastos y así se beneficiaba no solo el ganado, sino también especies como el venado. Protegían las fuentes hídricas, ya que entendían la importancia de su conservación no solo para los animales, sino para consumo humano.

\section{¿Reingreso del narcotráfico y nueva ola de violencia?}

A mediados de julio de 2018, en La Serranía se realizó una expedición biológica con la Fundación Omacha y la World Wildlife Foundation (WwF) a la cabeza. Un grupo numeroso ingresó a la zona sin ninguna precaución, pues no se habían presentado alteraciones de orden público en los últimos años. El grupo de investigadores se dirigió a Hato Mararay, colindante con el municipio de Mapiripán, quienes debían realizar análisis de peces 
se dirigieron hacia la confluencia del Caño Pauto con el Río Manacacías. Allí se encontraron

una especie de cambuche y sorpresivamente minutos después fueron abordados por la fuerza aérea, estuvieron sobrevolando bastante tiempo, luego llegaron cuatro helicópteros, los investigadores retrocedieron, se devolvieron hacia Mararay, ese sobrevuelo duro bastante tiempo y finalmente se escuchó un bombardeo (Hernández, comunicación personal, 2018).

A mediados de junio de 2018, Roberto Aya - Botalón, como amistosamente le decían sus conocidos - fue asesinado en circunstancias no esclarecidas. Esta noticia fue un duro golpe para Puerto Castro, pues desde la juventud había realizado trabajos del llano allí. Inició como mensual y terminó administrando el Hato Santa Teresita. Hacia el 15 de octubre de 2018 se presentó una situación de alteración de orden público en La Cristalina. Cuando el autor de este artículo se disponía a hacer una visita a la zona, los pobladores informaron de la presencia de estructuras para la transformación de la coca con una característica: eran cocinas ubicadas en los ríos y caños más caudalosos, lo que les facilitaba la movilidad de ser necesaria.

Dicha situación hace necesario ahondar en una investigación minuciosa sobre esta mutación del narcotráfico pues se podría inferir que ya no se hace uso de territorios grandes, sino de espacios pequeños cerca de los ríos por la vegetación que los cubre.

Antes uno encontraba infraestructura que duraba años, tanques, viviendas, en este momento no hay nada de eso, ponen unos plásticos para techos y es algo que se puede levantar rápido o que se puede dejar, porque la inversión es mínima (Hernández, comunicación personal, 2018).

Resulta interesante el hecho de que las cocinas móviles se ubicaran en la rivera de Caño Cumaral. La dificultad de ser encontrados sumado a la facilidad de escape vía fluvial hacen de los ríos el espacio perfecto para transformar coca. De hecho, Edimer Hernández se atreve a considerar la posibilidad de que la transformación la realicen en el mismo río, para mantener movimiento constante y no ser detectados.

\section{Conclusiones}

Los hallazgos de este estudio, indican que las formas de apropiación espacial están fuertemente ligadas a las actividades económicas propias de cada actor - ya sea endógeno o exógeno- Como muchas de las zonas rurales de Colombia, La Serranía no fue ajena a los procesos de colonización, violencia ni desplazamiento. El estudio de los procesos de apropiación espacial y de disputa por el control territorial en Colombia mostró que estos estuvieron fuerte e indudablemente ligados a la violencia y expansión de estructuras territarios 42-Especial 
armadas ilegales. Esta expansión, dada no solo en el marco de un conflicto armado, sino también de relaciones de poder y de intereses económicos, en la mayoría de casos convirtió los campos y veredas en espacios de miedo: "las personas empiezan a sentir, pensar y hablar de su lugar de vida de manera distinta, en formas ahora impregnadas de experiencias y memorias traumáticas, y de miedos y angustias" (Oslender, 2018, p. 80-81). Diana Ojeda (2016) destaca que en muchos casos, el despojo está soportado en la producción cotidiana de espacios de miedo.
Aunque la idea en la literatura que analiza la violencia y estudia el campo colombiano de que la ganadería y el paramilitarismo han hecho una perfecta simbiosis está arraigada, esta experiencia de investigación resulta contradictoria. En la tabla 2, se expresan con mayor claridad y brevedad las conclusiones a las que el autor ha llegado en este primer análisis de La Serranía de Manacacías, respecto a las transformaciones de los aspectos que en la tabla 1 se expusieron.

Tabla 2. Transformación de aspectos

\begin{tabular}{|l|l|}
\hline \multicolumn{1}{|c|}{ Aspecto } & \multicolumn{1}{c|}{ Transformación } \\
\hline $\begin{array}{l}\text { Organización } \\
\text { social }\end{array}$ & $\begin{array}{l}\text { La ganadería estableció una organización social y división del trabajo en mensuales, } \\
\text { vaqueros, caporales y administradores. Durante la expansión paramilitar, la } \\
\text { organización social se transformó para dar paso a una estructura comandada por sus } \\
\text { jefes. Así, los roles de la ganadería fueron reemplazados por aquellos de las cocinas } \\
\text { de transformación de la coca en pasta, vigilantes y lugartenientes. Actualmente la } \\
\text { organización social está dada por "machosolos", por la imposibilidad de conseguir } \\
\text { parejas que vivan en la vereda; son hombres de edad quienes administran los hatos y } \\
\text { cuidan del poco ganado que hay en las propiedades. }\end{array}$ \\
\hline $\begin{array}{l}\text { Actividad } \\
\text { productiva }\end{array}$ & $\begin{array}{l}\text { La ganadería extensiva inició con fuerza en las décadas del 60 y 70 en ambas veredas. } \\
\text { Con el ingreso de los paramilitares, esta fue reemplazada por el narcotráfico. Las } \\
\text { cocinas para transformar la hoja de coca en cocaína se dispersaron a lo largo de las } \\
\text { dos veredas. En la actualidad muy pocos hatos conservan su vocación ganadera; el } \\
\text { petróleo, la palma y los maderables son alternativas para los pocos habitantes que } \\
\text { quedan. }\end{array}$ \\
\hline $\begin{array}{l}\text { Estructura de la } \\
\text { tenencia de la } \\
\text { tierra }\end{array}$ & $\begin{array}{l}\text { Esta estructura estaba dada por grandes hatos de 30 000 ha y paulatinamente se fueron } \\
\text { dividiendo entre los miembros de las familias que llegaban a través del efecto llamada. } \\
\text { Con el ingreso de los paramilitares, muchos propietarios huyeron de la violencia y } \\
\text { los hatos quedaron a merced de estas estructuras. Muchos otros tuvieron que vender } \\
\text { sus tierras bajo la presión de las armas. En La Cristalina, la división del Hato Cejalito } \\
\text { promovió la fundación de 29 fincas, muchas de las cuales fueron vendidas por ser } \\
\text { improductivas. Hoy en día, muchas de esas fincas son propiedad de unos cuantos } \\
\text { personajes con gran capacidad económica, algunas otras propiedades han sido vendidas } \\
\text { a plantaciones de maderables. }\end{array}$ \\
\hline
\end{tabular}




\begin{tabular}{|l|l|}
\hline \multicolumn{1}{|c|}{ Aspecto } & \multicolumn{1}{c|}{ Transformación } \\
\hline Ejercicio de \\
territorialidad & $\begin{array}{l}\text { La ganadería permitió en un inicio controlar grandes extensiones de tierra con relativa } \\
\text { facilidad. El hecho de encontrarse con una cabeza de ganado en la sabana significaba } \\
\text { que la tierra ya tenía propietario. Las cercas y los límites artificiales se convirtieron } \\
\text { en las herramientas más eficaces para controlar el territorio. Con la llegada del } \\
\text { paramilitarismo, el ganado como herramienta del ejercicio de territorialidad fue } \\
\text { reemplazado por la ocupación a través de tropas, así como la compra de predios por } \\
\text { la fuerza y la definición de las zonas a las que podían acceder los pobladores, los } \\
\text { horarios para transitar y las limitaciones de ingreso a las veredas. En la actualidad, } \\
\text { los propietarios con gran poder adquisitivo han instalado cámaras de seguridad para } \\
\text { controlar el paso de individuos a través de las servidumbres. }\end{array}$ \\
\hline $\begin{array}{l}\text { Apropiación } \\
\text { espacial }\end{array}$ & $\begin{array}{l}\text { La ocupación de La Serranía por parte de los colonos estuvo dada a través del efecto } \\
\text { llamada y, nuevamente, por la ganadería. La característica identitaria resulta de suma } \\
\text { importancia para este momento, pues La Serranía dejó de ser una sabana “despoblada } \\
\text { y sin propietario" y pasó a ser un territorio dotado de cargas simbólicas y valóricas que } \\
\text { la convirtieron en una extensión del ser. Los paramilitares veían en La Serranía la posi- } \\
\text { bilidad de desarrollar sus actividades ilícitas por ser una región de grandes extensiones } \\
\text { lejos del control estatal. Se apropiaron del espacio veredal a través de la fundación de } \\
\text { los caseríos ubicados estratégicamente y de la conformación de campamentos, sitios de } \\
\text { entrenamiento y la construcción de pistas para avionetas. Al día de hoy, la apropiación } \\
\text { espacial está dada a partir de la negociación de los predios con representantes de los } \\
\text { sectores agroindustriales y petroleros, quienes se presentan como la única alternativa } \\
\text { para los propietarios de deshacerse de unas tierras que representan para ellos una carga. }\end{array}$ \\
\hline
\end{tabular}

Fuente: elaboración propia.

\section{Referencias}

Arias, J. (2004). Ganadería, paisaje, territorio y región. Una historia ecológica y social de la Orinoquía colombiana. Instituto Alexander Von Humboldt. Recuperado de https://bibliodarq. files.wordpress.com/2014/12/ ariasvanegas- $j$-ganaderc3ada-paisajeterritorio-y-regic3b3n-una-historiaecolc3b3gica-y-social-de-la-orinoquiacolombiana.pdf

Ávila, A. (2011). La economía de los paramilitares. Bogotá: Editorial Debate.
Avila Sánchez, H. (2015). Recent trends in rural geography studies. Theoretical developments and research areas in Latin America. Investigaciones geográficas, (88), 75-90. https://www.doi. org $/ 10.14350 /$ rig. 44603

Aya, R. (2015). Comunicación personal.

Carabalí, A. (2009). El Llano, un territorio forjado entre dos modelos de espacio. Atelié Geográfico, 3(2), 1-18. https:// www.doi.org/10.5216/ag.v3i2.7289 Castillo, F. (1987). Los jinetes de la cocaina. Recuperado de http://www.derechos. org/nizkor/colombia/libros/jinetes/ territarios 42-Especial 
Corporación para el Desarrollo Sostenible del Área de Manejo Especial La Macarena -Cormacarena-. (2014). Caracterización regional biofisica $y$ socio-económica de la Iniciativa de Conservación Alto Manacacias. Documento inédito.

Cubillos, R. (2011). Transformaciones territoriales a partir del abandono y despojo de tierra asociado a la acción de grupos armados caso María la Baja departamento de Bolívar. Recuperado de https://www.javeriana.edu.co/ biblos/tesis/eambientales/tesis95.pdf Díaz, I. (2016). Palma, Estado y región en los Llanos colombianos (1960-2015). En A. Ulloa \& S. Coronado (Eds.), Extractivismos y posconflicto en Colombia: retos para la paz territorial (pp. 167200). Bogotá: Editorial Universidad Nacional de Colombia - CINEP.

Entrevistado H. (2018). Comunicación personal.

Fajardo, D. (s.f.). Orinoquia: Colonización, frontera y estructuración social. Recuperado de http://bdigital.unal. edu.co/7313/1/ORINOQUIA_ COLONIZACION_Y_ESTRUCTURACION_TERRITORIAL.pdf

Fajardo, D. (2002). Para sembrar la paz hay que aflojar la tierra. Bogotá: Editorial Universidad Nacional de Colombia.

Fundación Puerto Rastrojo. (2014). Caracterización socioeconómica y biológica del poligono del Alto Manacacias seleccionado por Parques Nacionales Naturales como área potencial para la declaración de un área protegida. Documento Inédito.

García Abad, R. (2003). Un estado de la cuestión de las teorías de las migraciones. Historia contemporánea, 26, 329-351.

García Pérez, P. (2016). La privatización de la violencia en Colombia y las AUC: de las autodefensas al paramilitarismo contrainsurgente y criminal. Revista Izquierdas, 27, 230-255. https://www.doi.org/10.4067/ S0718-50492016000200009

Giménez, G. (2001). Cultura, territorio y migraciones. Aproximaciones teóricas. Revista Alteridades, 11(22) 5-14.

Gutiérrez Sanín, F. (2015). Estructura organizacional de los paramilitares y derechos de propiedad en el campo (1982-2017). Análisis Político, 27(82), 3-21.

Gutiérrez Sanín, F. (2014). Propiedad, seguridad y despojo: el caso paramilitar. Estudios Socio-Jurídicos, 16 (1), 43-74. https://www.doi.org/10.12804/ esj16.1.2014.01

Gouëset, V. (1999). El territorio colombiano y sus márgenes. La difícil tarea de la construcción territorial. Revista Territorios, 1, 77-94.

Hernández, R. (2015). Comunicación personal.

Hernández, E. (2018). Comunicación personal.

Ibáñez, A., \& Querubín, P. (2004). Acceso a tierras y desplazamiento forzado en Colombia. Bogotá: Centro de Estudios 
de Desarrollo Económico Universidad de los Andes.

Jaramillo, J., Mora, L., \& Cubides, F. (1986). Colonización, coca y guerrilla. Bogotá: Editorial Universidad Nacional de Colombia.

Marchena, R. (2015). Comunicación personal.

Molano, A. (1989). Aproximación al proceso de colonización de la región del Ariari-Guejar-Guayabero. Recuperado de http://bdigital.unal.edu. co/1435/7/05CAPI04.pdf.

Medina, C. (2005). La economía de guerra paramilitar: una aproximación a sus fuentes de financiación. Análisis Politico, 18 (53), 77-87.

Ojeda, D. (2016). Los paisajes del despojo: propuestas para un análisis desde las reconfiguraciones socioespaciales. Revista Colombiana de Antropologia, 53(2), 19-43.

Oslender, U. (2018). Terror y geografía: examinar múltiples espacialidades en un mundo "aterrorizado". Clepsidra. Revista Interdisciplinaria de Estudios sobre Memoria, 5(9), 68-85.

Parques Nacionales Naturales de Colombia. (2017). Informe final: caracterización social, económica y cultural de la Zona Manacacías. Documento inédito. Bogotá.

Rey Sabogal, C. (2013). Análisis espacial de la correlación entre cultivo de palma de aceite y desplazamiento forzado en Colombia. Revista Análisis Político, $32(61), 683-718$.
Rey, E. (2015). Comunicación personal.

Rey, G. (2018). Comunicación Personal.

Rodríguez, I. (2014). Despojo, baldíos y conflicto armado en Puerto Gaitán y Mapiripán (Meta, Colombia) entre 1980 y 2010. Estudios Socio-Jurídicos, 16(1), 311-338. https://www.doi. org/10.12804/esj16.1.2014.08

Rojas López, J. (2016). La reterritorialización de un espacio de frontera. El Llano alto occidental de Venezuela, 1950-2000. Procesos Históricos, (30), $59-76$.

Sandoval, R. (2015). Tierra, conflicto y posacuerdo. Bogotá: ARFO editores.

Sierra, J. (2017). Comunicación personal. Sierra, J. (2014). Comunicación personal. En Fundación Puerto Rastrojo (Ed.), Caracterización socio-económica y biológica del polígono del Alto Manacacías seleccionado por Parques Nacionales Naturales como área potencial para la declaración de un área protegida. Documento inédito.

Vega Cantor, R. (2012). Colombia, un ejemplo contemporáneo de acumulación por desposesión. Theomai, 26, 1-24.

Verdad Abierta. (2008). 'Cuchillo', Pedro Oliveiro Guerrero. Recuperado de https://verdadabierta.com/perfilpedro-oliveiro-guerrero-alias-cuchillo/ Verdad Abierta. (2009). Asi fue la guerra entre Martín Llanos y Miguel Arroyave. Recuperado de https://verdadabierta. com/asi-fue-la-guerra-entre-martinllanos-y-miguel-arroyave/ territarios 42-Especial 
Vergara, W. (2010). La ganadería extensiva y el problema agrario. El reto de un modelo de desarrollo rural sustentable para Colombia. Revista Colombiana de Ciencia Animal, 3, 45-53.

Woods, M. (2009). Rural geographies: blurring boundaries and making connections. Progress in Human Geography,
33(6), 849-858. https://www.doi. org/10.1177/0309132508105001

Zuluaga, J. (2002). Guerra prolongada, negociación incierta: Colombia. En R. Briceño-León (Comp.), Violencia, sociedad y justicia en América Latina, (pp. 339-367). Buenos Aires: Clacso. 